\title{
Looking for a Bookstore in Town: Intellectual Readers and the Death of "Gutenberg Galaxy"
}

\section{Maksym W. Kyrchanoff}

Voronezh State University. Voronezh, Russia. Email: maksymkyrchanoff[at]gmail.com

\begin{abstract}
The author analyses the problems of erosion of the book culture and the role of bookishness in the contemporary Western and Russian identities. While analysing the processes of disappearance and displacement of bookshops, the author presumes that culture of bookstores and communication subcultures in them cannot compete with networks and e-commerce. It is assumed that the logic of capitalism favours the progress of on-line bookstores, specialising in the serial and mass literature while independent bookstores prefer to sell intellectual, non-fiction, and academic books that are not interesting to consumer readers of mass culture. The author tries to analyse causes of private non-mass bookstores crisis. The author believes that intellectuals of $2000 \mathrm{~s}$ were optimistic in their prognosis for the development of bookstores as spaces of cultural initiatives. By the end of 2020, due to the coronavirus pandemic, the number of independent bookstores decreased significantly when on-line bookstores occupied their place. It is assumed that the cultures of reading, book collections, personal libraries lost the positions they held in the 20th century and even in the first decade of the 21st century. The author presumes that independent bookstores became cultural ghettos and intellectual reservations, when net bookstores became successful actors of the mass culture. In general, it is predicted that heterogeneous, regionally localised minority book cultures and reading strategies of the New Medievalism may replace the "mass" book as a cultural institution of a modern political imagined communities as elements of the dying Gutenberg Galaxy with its heterogeneous national identities.
\end{abstract}

\section{Keywords}

Books; Urban Cultural Spaces; Reading; Book Trade; Independent Bookstores; Bookstores in the Urban Cultural Geography; Net Bookstores; E-Commerce; Bookstore Closures; the Gutenberg Galaxy Crisis 


\section{В поисках книжного магазина в городе: читатели-интеллектуалы и отмирание «Галактики Гутенберга»}

\section{Кирчанов Максим Валерьевич}

Воронежский государственный университет. Воронеж, Россия. Email: maksymkyrchanoff[at]gmail.com

\section{Аннотация}

Автор анализирует проблемы эрозии культуры книги и роли книжности в современных идентичностях Запада и России. Анализируя процессы исчезновения и вытеснения книжных магазинов, автор полагает, что культура книжных магазинов и субкультура коммуникации в них не может конкурировать с книжными сетями и Интернет-торговлей. Предполагается, что логика развития капитализма благоприятствует прогрессу сетевых книжных магазинов, втянутых в торговлю серийной и массовой литературой, в то время как книжные магазины, не являющиеся сегментами сетей, предпочитают продвигать интеллектуальные или научные книги, которые фактически не интересны для массового читателя как потребителя массовой культуры. Автор пытается проанализировать, почему отмирают частные немассовые книжные магазины. Автор полагает, что если в 2000-е годы российские интеллектуалы были оптимистичны в своём восприятии перспектив развития книжных магазинов как пространств культурных инициатив, то к концу 2020 года под влиянием пандемии коронавируса число независимых книжных магазинов значительно сократилось, а их место было занято сетевыми магазинами. Предполагается, что культуры чтения, приобретения книг, развития книжных магазинов и формирования личных библиотек утратили те позиции, которые они занимали в XX веке и даже в первое десятилетие XXI столетия. Автор полагает, что независимые книжные магазины становятся культурными гетто и интеллектуальными резервациями, а сетевые книжные магазины входят в число акторов массовой культуры обществ потребления. В целом, прогнозируется, что на смену «массовой» книги как культурного института модерновой политической нации и воображаемых сообществ эры Модерна как элементов отмирающей «Галактики Гутенберга» с ее гетерогенными национальными идентичностями могут прийти гетерогенные, регионально локализованные миноритарные книжные культуры и стратегии чтения Нового Средневековья.

\section{Ключевые слова}

книги; урбанистические культурные пространства; чтение; книжная торговля; независимые книжные магазины; книжные магазины в культурной географии города; сетевые книжные магазины; Интернет-торговля; закрытие книжных магазинов; кризис «Галактики Гутенберга»

Это произведение доступно по лицензии Creative Commons «Attribution» («Атрибуция») 4.0 Всемирная 


\section{Введение}

В историографии, сфокусированной на изучении новой истории Запада в значительной степени распространён стереотип, ставший фактически изобретённой историографической традицией о том, что книга и книжная культура были среди тех факторов и стимулов, который сформировали канон западной идентичности или, как минимум, оказали существенное влияние на процессы её генезиса и последующего развития. Что касается утверждений об уникальной роли книги и культуры чтения в развитии цивилизации, то они успели стать общим местом, а апелляции к ним в историографии были столь часты, что эти сентенции стали восприниматься как проявление дурного историографического тона.

Тем не менее, коллективные представления о книге, возникшие в рамках модерных идентичностей, с одной стороны, и опыт нескольких поколений западных интеллектуалов, с другой, вероятно свидетельствует о значительной роли именно книжной культуры в истории Запада. Вместе с тем, история современного Запада фактически неотделима от истории капитализма и, если мы обращаемся к анализу различных форм и проявлений феномена книги и книжности, то он будет неполным без обращения к проблемам книжного рынка и книжных магазинов как его локального проявления или частного случая. Развитие массовой культуры и общества потребления во второй половине XX века оказало самое существенное влияние на эти два явления.

Если в XX веке книжная торговля периодически пребывала в состоянии роста, а книжный рынок Запада контролировался несколькими транснациональными издательскими домами и сетевыми книжными магазинами в капиталистических странах и государственными книготорговыми сетями в социалистических обществах, то в XXI столетии ситуация в значительной степени изменилась, став качественно и содержательно иной. Если в XX веке на издательском и книжном рынке действовали как крупные сетевые игроки, так и малые издательства и частные книжные магазины, которые в западных обществах нередко представляли собой примеры семейного бизнеса, развиваемого и продвигаемого на протяжении нескольких поколений, то в XXI веке ситуация выглядит иначе: малым игрокам и участникам рынка все сложнее конкурировать с национальными или транснациональными конкурентами как в деле книгоиздания, так и книготорговли.

Дискурс модерна, как и постмодерна, в гуманитарных науках в той или иной степени основан на образе смерти, кратких или пространных размышлений о ней. Фактически современные гуманитарные исследования, который генетически восходят к марксизму, стали наукой об отмирании / умирании или смерти одних социальных, политических, экономических институтов и отношений, на смену которым приходили другие формы организации обще- 
ства в целом, его культурных и интеллектуальных пространств в частности. Урсула Ле Гуин, американская писательница, констатировала, что

люди любят говорить о чьей-нибудь смерти - книги, истории, природы, Бога или аутентичной каджунской кухни. Во всяком случае, люди с эсхатологическим складом ума (Le Guin, 2016).

Примечательно, что среди этих, как правило, социальных и культурных умирающих или отмирающих явлений на первом месте стоит именно книга.

Пандемия коронавируса в 2020 году оказала существенное влияние на книжную торговлю и книжность, став не только темой новостной повестки дня, но и значительно повлияв на процессы закрытия книжных магазинов и вытеснения книжных магазинов с культурных и интеллектуальных карт современного урбанизированного пространства. 2020 год актуализировал процессы виртуализации как экономики, так и гуманитарной сферы, что неизбежно отразилось на книжных магазинах как культурной институции. Если 1990-е, 2000-е и 2010-е годы были отмечены тенденциями постепенной редукции книги, сокращением её роли, виртуализации текстов, смены пространств и территорий их бытования и функционирования, то пандемия в сочетании с её негативными экономическими эффектами стала тем фактором, который стимулировал волну закрытия книжных магазинов, культурные и интеллектуальные последствия которой, вероятно, ещё следует изучить.

Поэтому тенденции закрытия частных несетевых книжным магазинов и сокращение доли на рынке малых издательств, не способных эффективно конкурировать с крупными участниками рынка стало общей тенденцией как в России, так и на Западе.

\section{Цель и задачи статьи}

Трансплантируя некоторые западные подходы, но стараясь избежать иллюстративно-цитатного изложения, порой процветающего в «продвинутых» интеллектуальных российских журналах, в центр авторского внимания в данной статье мы ставим проблемы кризиса, вытеснения с рынка и, как результат, закрытия малых книжных магазинов, специализирующихся на немассовой, но на интеллектуальной литературе. Эти процессы, вероятно, стали следствием как глобализации, так и массовизации культурного дискурса, которые почти сделали чтение и сопутствующие явления достоянием историков (Chartier, 1996).

Исходя из этого, целью статьи является анализ процессов эрозии и разрушения культуры чтения и продвижения интеллектуальной книги в обществе потребления в контекстах вытеснения с рынка книжных магазинов, которые специализировались именно на подобной литературе. Что касается задач статьи, то они могут быть сформулированы следующим образом: анализ процессов эрозии традиционной книжной или либроцентричной модели культуры в обществе массового потребления; анализ падения книжного 
бизнеса в контекстах кризиса продвижения интеллектуальной книги как содержательно чуждого культурного проекта и контента в рамках массовой культуры; анализ перспектив дальнейшего кризиса либроцентричной модели культурной идентичности в условиях одновременной виртуализации и глобализации.

\section{Книги и «книжное» в современных городских пространствах: от присутствия и пребывания до маргинализации и отмирания}

Если к концу 2000-х годов, интеллектуалы были настроены относительно оптимистично, полагая, что книга занимает стабильное место в экономике и в современной урбанистической среде, то социальная, культурная и экономическая динамика второго десятилетия 21 века внесла в эти констатации определённые коррективы, актуализировав не только общие трансформации урбанистического в ущерб культурному (Tskhvediani, 2017), но и проблемы эрозии книжной культуры, превращения книжности в социальный рудимент и культурный архаизм, что выразилось в вытеснении книги из упомянутых выше пространств, сужении сферы её пребывания до крупных сетей, церковных лавок и иррегулярных букинистических лотков.

Постепенно в интеллектуальных средах стал все более часто встречаться и даже доминировать алармистский тон и пессимистический настрой относительно перспектив культуры чтения в её различных измерениях в современном мире. Если под влиянием триумфа «Галактики Гутенберга» и с «изобретением книгопечатания культура устного повествования исчезла, мастерство рассказчика обесценилось, индивидуализм в обществе укрепился, потому что книга и газета не требуют отношений от людей» (Chiabrishvili, 2015), то в результате культурной глобализации книга имеет все шансы разделить судьбу устного предания.

Постепенное отмирание и исчезновение книжных магазинов существенно влияет на то, что обычно называется «этнографией чтения», интерпретирующей это явление в контекстах самых разнообразных культурных и интеллектуальных практик и активностей. Закрытие книжных магазинов, сужение и редукция географии чтения ведёт к его превращению именно в «этнографический» и почти «музейный» факт, связанный с функционированием архаичных и модерных культур прошлого, которые не смогли конкурировать с массовой литературой, и, как результат, с книжными сетями. Американский критик и журналист Чандра Джонсон, с другой стороны, комментируя опасения об отмирании книжных магазинов как социальных и культурных институций, подчёркивает, что их

потенциальная кончина также актуализирует вопрос о том, что было потеряно, если бы книжные магазины и бумажные книги пошли по пути музыкальных 
магазинов, сократившись до нескольких стойких приверженцев, продающих то, что большинство теперь считает специальными предметами? (Johnson, 2016).

Социальная и экономическая динамика как на Западе, так и на Востоке свидетельствует о том, что книги имеют все шансы стать предметами специального (интеллектуального) потребления, а магазины, подобно церквям в секуляризированном Западе, станут формой культурного гетто. Книга перестаёт быть массовой, если речь идет об интеллектуальной или научной литературе, которая и в более ранние годы не отличалась значительными тиражами. Николоз Агладзе, грузинский культурный и литературный критик, комментируя особенности формовки современного постлиброцентриченого мира, полагает, что в нем книга все чаще и чаще представляет собой

мёртвый текст, а точнее текст, рождённый для смерти. Он отлично выполняет функцию изображения на стене: без лишних усилий читатель за секунды чувствует то, что хочет. Однако после того, как он сфотографирует это в своей памяти, фокусировка закончится. В этом разница между иллюзионистом и фокусником: один лжец, а другой - нет (Agladze, 2017).

Комментируя особенности потребления в обществе, где масс-культура стала парадигмой, Давит Галаишвили полагает, что

на сегодняшний день для человека, занимающегося рутинной деятельностью, средством ухода от реальности стал продукт, созданный массовой кино- и музыкальной индустрией, создающий определённые образы и стереотипы, которая добровольно или невольно ставится на службу капиталу и образует прочную основу для существующего экономического производства (Galaishvili, 2018).

Примечательно, что среди всех этих формально культурных институций фактически нет места книги и, поэтому, она отсутствует, самоустранившись и будучи выставленной за пределы культурного мэйнстрима на периферию рудиментарных и архаичных культурных активностей. Поэтому, в условиях современного общества потребления эти социальные и культурные роли иллюзиониста и фокусника начинают играть книжные магазины с той лишь разницей, что одни работают и ориентированы на массового читателя и удовлетворение его потребительского вкуса, а другие - на обслуживание и, тем самым, поддержку существования культурных гетто и интеллектуальных резерваций.

Если книжные фестивали раньше были поводом для встреч писателей и издателей (Sastumlishvili, 2019), то в мире, который перестанет быть либроцентричным и, где число книжных магазинов имеет все шансы численно сравняться с числом дорогих антикварных, книжные фестивали актуализируют роль и функции средневекового сознания, став почти религиозными событиями, сравнимыми с ежегодными паломничествами к местам упокоения мощей особо чтимых святых. Закрытие магазинов религиозной литературы, издаваемой различными протестантскими деноминациями в США, имевшее место в 2019 и 2020 годах (Graham, 2019), вероятно, свидетельствует о том, 
что такой сценарий является вероятным. Если на протяжении современной истории «книжные магазины, когда-то столь же распространённые, как люстры Дейла Чихули, сыграли неотъемлемую роль в нашей экосистеме письменного слова и городской культуры» (Fischer, 2013), то современная глобальная экономика вкупе с низкой социальной ответственностью бизнеса грозит превратить новейшую историю книжных магазинов и культуры чтения в еще одну страницу в культурной истории «трагедии общин» (Hardin, 1968), а читатели книг, а не электронных гаджетов, социально будут маргинализированы в неменьшей степени, чем английские крестьяне, пострадавшие в результате процессов огораживания.

Вероятно, отмирание книжных магазинов станет и тем фактором, который простимулирует растущие тенденции к национальной изоляции: число потребителей книги как культурного продукта сократиться, а сама книга перестанет быть источником знакомства с опытом Других. В этой ситуации этнические нации периферийных регионов Европы, вероятно, смогут более эффективно сохранять свои идентичности, но, вместе с тем, число знающих и идентифицирующих их Других также сократится. Книжная экспансия европейских периферийных интеллектуалов, которые в марте 2019 года относительно оптимистически полагали, что

грузинские классики интересуют иностранных читателей, так как дают им возможность ознакомится с оригинальной и совершенно иной культурой, новым этнографическим миром неизвестных традиций (Agladze, 2019),

окажется маловероятной. Нельзя исключать, что национальные книжные традиции и культуры оказавшись в состоянии изоляции подвергнуться провинциализации, хотя именно такие сообщества, этнически выделенные из массива соседних наций, смогут сохранить свои книжные культуры со всеми их атрибутами, включая книгоиздание и книжный рынок, но они будут удовлетворять исключительно внутренний спрос.

На протяжении 2000 - 2010-х годов книжные магазины в мире постепенно не выдерживали конкуренции с новыми формами организации в сфере книжного бизнеса, а интеллектуалы в различных странах (Kevanishvili, 2019) стремились актуализировать инициативы, направленные на визуализацию книги и её большую представленность в современных культурных пространствах. Комментируя закрытие книжных магазинов, американский критик Джэй Оливер Конрой подчёркивает, что они обречены исчезнуть как «таксофоны, мастерские по ремонту пишущих машинок и жилье среднего класса» (Conroy, 2019). Постепенная маргинализация книжности с вероятным последующим исчезновением книги как культурного и социального института может стать следствием постмодернистского сдвига, который привёл к исчезновению различий между «высоким» и «низким» в культуре. Поэтому 
новый клип Мадонны, любая телекомедия, реклама дезодоранта, предвыборная речь или граффити - такие же интересные объекты для исследования, как стихи Байрона или проза Флобера (Chigvinadze, 2010).

Примечательно, что в этом перечислении книги, формально принадлежащие дискурсу «высокой» культуры, оказываются обесцененными до уровня продуктов массовой культуры. В этой ситуации 2000 - 2010-е года стали временем, когда «книжные магазины постепенно исчезали один за другим» (O'Connor, 2016). Анализируя подобные ситуации, современные интеллектуалы (Kukhalashvili, 2013) признают, что хотя защита книги важна как символический акта, потому что они бессильны изменить массовые читательские интересы и предпочтения, которые постепенно мигрируют в направлении электронных форматов.

В 2011 прекратила существование американская сеть книжных магазинов «Borders». Временный вакуум на американском рынке заполнили другие сети (Carrion, 2017), а малые магазины оказались фактическими аутсайдерами, что, будучи универсальной ситуацией для книжного рынка в ряде стран, свидетельствовало о первых симптомах кризиса книжной культуры со всеми её производными - от малых издательств и книжных с их преимущественно интеллектуальным и узко сегментированным ассортиментом до крупных сетей. Комментируя особенности современной культурной ситуации, Гиорги Лобжанидзе вынужденно констатировал, что «однажды я обнаружил, что почти все люди, которыми я тогда дорожил, теперь находятся на деревенском кладбище» (Dvali, 2020), что вполне трансплантируемо на современные культурные ситуации, где интеллектуалы оказываются в культурных гетто и резервациях частично по собственной вине и от части в следствие усиления массовой культуры, почти ставшей единственной культурной парадигмой. Нукри Шошиашвили, грузинский историк, выразил в значительной степени аналогичную идею несколько иначе, подчеркнув, что современная междисциплинарная историография все больше начинает верить в то, что «историческая реальность - это литературный артефакт» (Shoshiashvili, 2016). Если проецировать столь пессимистическое наблюдения на современные социальные пространства, то книга имеет все шансы стать сначала культурным рудиментом, а потом и артефактом, оказавшись в одном культурном пространстве вместе с отмершими атрибутами культуры классической и культуры массовой, включая рукописные свитки, виниловые пластинки, видеокассеты VHS, что может превратить книжные магазины и саму книгу как культурное явление в не более чем часть современной мемориальной культуры.

Факты сокращения числа книжных магазинов и их последующего закрытия хорошо известны: в 2012 году в Санкт-Петербурге прекратил работу независимый книжный магазин «Борхес», в 2013 году под угрозой закрытия оказался пермский независимый книжный магазин «Пиотровский». В 2016 году по экономическим причинам закрылся ижевский «Букинист». 2020 год стал не только годом пандемии коронавируса, но и годом массового закрытия 
книжных магазинов, которые специализировались на продаже нон-фикшн, интеллектуальной и научной литературы, которая практически недоступна в крупных сетях или представлена в них в несравнимо меньших объемах. В 2019 году в Новосибирске закрылся независимый книжный магазин «Плиний Старший». В 2019 - 2020 годах в Москве закрылся магазин «Академкнига». В феврале 2020 года в Киото закрылся раннее культовый книжный магазин «Junkudo» (Takamitsu Sawa, 2020). Осенью 2020 года в Воронеже прекратил работу книжный клуб «Петровский». Их закрытие поставило перед местными сообществами вопрос, единый ответ на который представляется маловероятным: если судьбы личных библиотек post mortem описаны в интеллектуальной публицистике, то судьба тех книг, что закрывавшиеся магазины не успели и не смогли продать, остается неясной.

Несмотря на попытки западных интеллектуалов проанализировать, «как отрасли, организации и бизнес-лидеры изобретают себя заново перед лицом радикальных технологических изменений в контекстах розничной торговли сейсмические сдвиги влияют на то, как потребители взаимодействуют с онлайн-магазинами, крупными торговыми площадками и местными розничными торговцами» и в этом контексте предполагать, что «независимые книжные магазины дают повод для надежды для местных сообществ» (Raffaelli, 2020), их прогноз в случае его трансплантации в российские локальные и региональные реалии оказывается ошибочным, неэффективным или вовсе неприменимым потому что, если на Западе мы можем анализировать действительно независимые проекты малых книжных издательств и магазинов (Burton, 2006; Childress, 2017; Miller, 2008), то в российском случае мы имеем дело с побочными бизнес-проектами, попытками улучшения имиджа крупного бизнеса, имитирующего социальную и культурную ответственность, для которого книжные магазины - не более чем временные инвестиции в изначально убыточные проекты.

Причины отмирания книжных и их уникальной культуры, на первый взгляд, могут быть сведены к особенностям современного капитализма и нежеланием бизнес-сообщества нести социальную ответственность, поддерживая убыточные книжные магазины. Такая точка зрения, хотя и может показаться привлекательной и даже правильной для определенной части общества, тем не менее, описывает проблему односторонне. Анализируя кризис книжных магазинов как культурной институции, во внимание необходимо принимать и общекультурные мутации, и трансформации общества потребления, описывая которые Илиа Урушадзе и Гиорги Пирцхалаишвили, пытаются сконструировать культурный облик типичного читателя-потребителя, который

после беспокойного сна заходит в книжный магазин и заказывает три книги на завтрак, обед и ужин. Официант, уточнив, каковы индивидуальные вкусы заказчика, входит на кухню и передаёт заказ шеф-повару. Повар зовёт издателя, издатель - писателя, писатель - жену. Все три книги готовы за двадцать минут. Потребитель литературы пробует продукт на вкус, мерно двигая челюстями. 
Его надежды не оправдались. Болит живот. От удивления и досады, недовольно причмокивая языком, он клянётся, что никогда больше не появится этом книжном магазине.... ему хотелось творческой и оригинальной книги... расслабьтесь... вы получили совершенно бесполезную массу (Urushadze \& Pirtskhalaishvili, 2018).

В этой пространной цитате, конечно, можно найти и аллюзии с современной российской постмодернистской литературой, но, вероятно, в большей степени она порождена именно ростом массовой культуры, которая превратила книгу в продукт массового потребления наряду с другими атрибутами формально благополучной массовой культуры. Если пессимистические предположения грузинских интеллектуалов верны, то в конкуренции между книжным магазином и фуд-кортом в современных городских пространствах шансы первого кажутся ничтожными. Вместе с тем, сетевые магазины с их серийным и вполне предсказуемым ассортиментом оказываются более эффективными, так как фактически способны не только конкурировать друг с другом, но и вытеснять с рынка независимых игроков.

Кризисы и череда закрытия книжных магазинов как в России, так и на Западе свидетельствовали о неспособности поддержать «экосистему обычных книжных магазинов в долгосрочной перспективе» (Crain, 2019), а также актуализировали пессимистические прогнозы о кризисе «галактики Гутенберга» (McLuhan, 1962), на смену которой, в результате её постепенной эрозии, разрушения, размывания пределов, трансформации границ в подвижные фронтиры, может прийти качественно и содержательно другая организация общества, где книга утрачивает свои позиции социального и культурного института, будучи вытесненным из числа факторов, определяющих основные векторы и траектории развития идентичностей, раннее не существовавших вне либроцентричной системы координат, связанной с теми или иными языками как изобретёнными традициями наций, функционировавших в качестве воображаемых сообществ. Если до недавнего времени эта проблема интересовала почти исключительно интеллектуалов и писателей (Bradbury, 1953), иногда актуализируясь (исключительно благодаря инициативе последних) в текстах постмодернистских литератур (Kyrchanoff, 2016; Kyrchanoff, 2017), то пандемия 2020 / 2021 гг. содействовало её визуализации и более активному обсуждению в обществе.

\section{Fin de la belle époque, или сложности перехода к посткнижную эру}

Если в начале 2010-х годов интеллектуалы, хотя и разочаровались в постмодерне, тем не менее, они не предвидели размаха и глубины эрозии книжной культуры в конце десятилетия. В частности, Тинатин Мчедлидзе полагала, что

историю и общество можно читать как текст, что обусловило восприятием культуры как единого интертекста. В этом случае автор и читатель мертвы и их 
сознание состоит из цитат, то есть мир уже сказал все обо всем, постмодернизм лишён новаторства, а текст создаётся по принципу калейдоскопа... реальность это лишь представление о реальности... в одном тексте объединены разные стили и жанры. Постмодернистский текст - это группа корней, у которых нет основы (Mchedlidze, 2011).

В таком мире постмодернистского гипертекста фактически нет ни книги, ни места для книги в силу того, что традиционные аналоговые, «ламповые», формы книжности уступили своё место виртуальным технологиям, хотя некоторые владельцы частных книжных магазинов ведут посильную борьбу против цифровизации чтения - в частности, Шон Байтэлл демонстративно расстрелял устройство для чтения электронных книг, а постепенная миграция книги и её потребления онлайн ведёт к тому, что из современных урбанистических географий начинают исчезать книжные магазины.

Проблемы эрозии и размывания книжной культуры, а также падение престижа книги как культурного института и чтения как социальной и интеллектуальной практики стали заметны в 1990-е годы, но только глобализация массовой культуры в начале 21 века и пандемия коронавируса в 2020 году сделали эту проблему острой и насущной. Если раннее вопросы кризиса либроцентричных форм и моделей идентичности интересовали почти исключительно интеллектуалов, для которых присутствие книги и книжности было фактором их корпоративных и индивидуальных идентичностей, то в 2020 году эта проблема оказалась на повестке дня СМИ как национальных, так и мировых.

Сами участники книжного рынка, комментируя особенности присутствия как малых издательств, так и независимых книжных магазинов указывают на сокращение числа последних примерно в два раза за период с 2015 года, что неизбежно вело, с одной стороны, к общему падению рынка бумажной книги в рамках её ассимиляции массовой культурой как культурой потребления. С другой стороны, это содействовало и элитизации книжной культуры, сокращению числа её вероятных и возможных потребителей, вынужденных консолидироваться вокруг своих собственных субкультур и альтернативных идентичностей в ими же создаваемых резервациях-гетто. Поэтому массовая культура существенно изменила формы пребывания книги в обществе, в котором они обречены стать предметом коллекционирования или частью музейных экспозиций.

В дискурсе массмедиа влияние пандемии и её последствия для книжного бизнеса - от процесса издания до функционирования книжных магазинов как правило, сводятся к нескольким пунктам, которые, по мнению ряда авторов, в целом характеризуют ситуацию. Современные медиа относительно книги и чтения, с одной стороны, а также книжных издательств и магазинов, с другой, выдвигают несколько предположений, которые в целом составляют неутешительный диагноз социальной и культурной ситуации. В самом общем плане предполагается, что книжный бизнес, включая само книгоиздание и 
дальнейшую книжную торговлю, вошёл в число максимально пострадавших отраслей от последствий пандемии коронавируса по той причине, что издатели и книжные магазины понесли значительные потери, которые не только приведут к вероятному закрытию части книжных магазинов, но и росту цен на книги, содействуя превращению чтения в элитарную форму досуга, так как «потребление все больше превращается в инструмент конструирования социальной идентичности» (Koyava, 2018), о чем, например, уже свидетельствует рост аудитории малых книжных магазинов с узкой специализацией в больших городах, где сохранились несетевые книжные магазины, хотя эта тенденция имеет локальный, но не национальный характер.

Значительная часть книжных магазинов, специализацией которых является не массовая литература, но нон-фикшн, научная литература, книги по искусству, литературная классика не переживут пандемию, разорившись, что приведёт к резкому сокращению числа участников книжного рынка, одновременно запустив новые механизмы, при которых акторами книжной торговли становятся сами издатели и издательства. Примечательно, что этот шаг, вероятно, первый на пути к трансформации книги как социального и культурного института и чтения как интеллектуальной практики, так как потенциальной фокус-группой некоторых издателей станет узкая группа потребителей-интеллектуалов, которая вряд ли заинтересует издателей, ориентированных на публикацию массовой литературы.

Пандемия актуализировала и активизировала конкуренцию между малыми издательствами и связанными с ними магазинами с крупными сетями. Летом 2020 года один из двух крупнейших игроков российского книжного онлайн рынка магазин «Лабиринт» разорвал соглашения с малыми издательствами, например - с «Издательством Ивана Лимбаха» и «Другим издательством». Поэтому гуманитарная литература этих репутационных издательств оказалась недоступной на «Лабиринте», что актуализирует тенденции как фрагментации книжного рынка, так и культуры потребления в направлении выделения массового / серийного сегмента и его интеллектуальной альтернативы. Если первый действительно является массовым, то второй имеет все шансы стать интеллектуальным гетто и культурной резервацией потому, что именно малые издательства в постсоветской России частично «монополизировали» (в хорошем смысле этого слова) издание нон-фикшн и научной литературы в сфере гуманитарных наук. Эта тенденция, к сожалению, содействуют вытеснению интеллектуальных жанров на культурную периферию, так как на смену им идут жанры с более низкими входными требованиями к читателю, то есть массовые.

В этот процесс включились не только малые издательства и независимые магазины со специализацией на той или иной гуманитарной тематике, но и политически и идеологически мотивированные участники рынка, к которым относится издательство «Чёрная сотня», использующее формат малых книжных в сочетании с лекторием, что позволяет более эффективно продви- 
гать политический «месседж», издаваемых им книг, хотя некоторые авторы ничего предосудительного в подобной стратегии не видят, что отчасти верно: если рынок уничтожает малые интеллектуальные книжные издательства, продающие художественные тексты модернистов и постмодернистов, то нельзя исключать, что на гибель обречены и другие малые издательства и магазины, продающие тексты правых и «новых правых» политиков и интеллектуалов.

Если для массового читателя-потребителя имена авторов книг, издаваемых альтернативными издателями, ничего не говорят, то некоторые малые магазины стремятся сохранить свой нейтралитет, что не спасает их от актов антиинтеллектуального протеста, направленных против современной культуры, воспринимаемой правыми и левыми радикалами исключительно негативно. Поэтому общество потребления, вряд ли, создаст в рамках существующей экономической модели эффективные механизмы продвижения и продаж книг, ориентированных на самого разного интеллектуального читателя.

\section{Выводы}

Подводя итоги статьи, нам следует принимать во внимание ряд факторов, связанных с трансформацией книги как социального и культурного института и тех рудиментарных и архаичных форм книжности, которые на современном этапе ещё ограничено представлены в массовой культуре общества потребления.

Во-первых, культура как институт в обществе потребления, с одной стороны, и в эпоху виртуализации и глобализации, с другой, утратила те позиции, которые она занимала раннее. Если сравнивать роль книги как культурного явления, книжности как института и культуры чтения с более ранними периодами в истории Запада и России, то роль книжных факторов в обществе потребления существенно сократилась. Современные идентичности, порождённые политическими, культурными и социальными модернизациями, превратившие книгу в массовый институт эры Модерна, постепенно утрачивают свои либроцентричные основания, в большей степени становясь виртуальными и онлайновыми, в которой для книги как аналогового и оффлайнового культурного продукта и чтения как культурной практики и стратегии не остаётся места. Поэтому само чтение мигрирует онлайн в электронные и виртуальные пространства, где массовая культура стала доминирующим и определяющим фактором.

Во-вторых, книжные магазины в большей степени и книжные издательства в меньшей степени актуализировали свою роль культурных институций, но не в контекстах создания и продвижения культурного контента, но в качестве культурных гетто и интеллектуальных резерваций. Контент, предлагаемый малыми книжными магазинами, значительно отличается от массовой 
книжной продукции сетевых магазинов. Если массовые сети предлагают продукт изначально задуманный для общества потребления, то содержательно книги малых издательств и подобных им книжных магазинов маргинальны, так как число их потребителей не столь значительно, не массово и ограничено представителями интеллектуальных сообществ, которые, втягиваясь в виртуальную культуру, все чаще предпочитают заказывать книги онлайн, тем самым фактически превращая традиционный книжный магазин в излишний рудимент, промежуточное звено относительно как издателя, так и читателя.

Подобная ситуация актуализирует культурные и интеллектуальные роли этого сегмента книжного рынка в сохранении идентичностей. Например, не вызывает сомнений роль латышской, литовской, украинской или белорусской книги и национальных издательств в эмиграции в сохранении национальных идентичностей. В современной России книгоиздание и книготорговля на языках народов России играет аналогичную роль, но, к сожалению, именно такие издательские и книготорговые проекты в большей степени уязвимы от внешних рисков, пребывая под угрозой ассимиляции культур формального большинства или массовой культуры общества потребления, склонной не ассимилировать меньшинства, но имитировать и симулировать национальное в глобальном. Поэтому роль книги в развитии и сохранении дискурса, в воспроизводстве и продвижении канона идентичности характерна для целого ряда современных наций как воображаемых сообществ.

В-третьих, книжные магазины как культурные институции в современном мире в большей степени оказывается контролируемой и зависимой от внешних политических факторов и конъюнктур, а также тех идеологических предпочтений, производимых и воспроизводимых в их рамках. В современной культуре потребления сложилась уникальная ситуация одновременного сосуществования двух качественно и содержательно различных стратегий продвижения книги. С одной стороны, традиционный академический нон-фикшн попрежнему сохраняет свои позиции как оффлайн, так и онлайн, но, с другой, ему все сложнее конкурировать с новыми вызовами, представленными радикальными издательскими левыми или правыми проектами и связанными с ними стратегиями продвижения книги как культурного продукта, хотя культурная компонента в этой ситуации постепенно вытесняется политической и идеологической. Примечательно и то, что в этой ситуации академический нон-фикшн конкурирует, например, с правыми экстремистскими книжными проектами, так как и сугубо академической и крайне правой книге нет места на полках традиционных книжных сетевых магазинов.

В целом, книга как социальный и культурный институт, а также чтение как интеллектуальная практика в современном обществе потребления постепенно утрачивают свои позиции, уступая место формам массовой культуры потребления, представленной в том числе и национальными и транснациональными сетями, рассчитанными на производство и воспроизводство унифицированного книжного продукта лишь формально интегрированного в национальные 
культурные контексты и пространства, имитируя национальный контент, но предлагая масс-культовый «месседж». Вероятно, в обозримой хронологической перспективе роль традиционных аналоговых форм книги, книжной культуры и чтения будет сокращаться; книжные магазины могут в ещё большей степени актуализировать роль культурных и интеллектуальных гетто и резерваций, оформленных в том числе и по национальному и языковому принципу в современном глобализирующемся мире; книга рискует стать именно культурным институтом, доступным и интересным преимущественно интеллектуалам, но малопонятным и непривлекательным для массового читателя как потребителя.

На смену «массовой» книге для модерной политической нации как воображаемого сообщества эры Модерна и, вероятно, отмирающей «Галактики Гутенберга» с её гетерогенными моделями идентичности, классифицируемой по множественным национальным и политическим признакам, могут прийти гетерогенные и, вместе с тем, миноритарные книжные культуры и стратегии чтения Нового Средневековья...

\section{Список литературы / References}

Agladze, N. (2017, September 11). Suite about the city and water, or why books are sold. Retrieved from

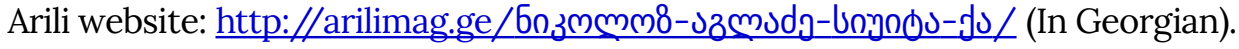

Agladze, N. (2019, March 2). Classics and modern. Retrieved from Arili website: http://arilimag.ge/

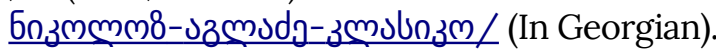

Bradbury, R. (1953). Fahrenheit 451, NY.: Ballantine Books.

Burton, B. (2006). The King's English: Adventures of an independent bookseller, L.: Gibbs Smith.

Carrión, J. (2017). Bookshops: A Reader's History. New York: Biblioasis.

Chartier, R. (1996). Culture écrite et société. L'ordre des livres (XIVe-XVIIIe siècle) [Written culture and society. The order of books (14th-18th century)]. Paris: Albin Michel. (In French).

Chiabrishvili, N. (2015, February 25). A man in Marshall McLuhan's "Global Village". Retrieved from Masts'avlebeli website: http://mastsavlebeli.ge/?p=4554 (In Georgian).

Chigvinadze, A. (2010, February 13). Kafka did not have a TV. Retrieved from Demo.ge website: https://www.demo.ge/index.php?do=full\&id=445 (In Georgian)

Childress, C. (2017). Under the cover: The creation, production, and reception of a novel, Princeton: Princeton University Press.

Conroy, J. O. (2019, March 4). Why are New York's bookstores disappearing? The city that produced so many authors is losing its bookshops to pressure from Amazon, changing reading habits and skyrocketing rents. Retrieved from The Guardian website:

https://www.theguardian.com/books/2019/mar/04/why-are-new-yorks-bookstoresdisappearing

Crain, C. (2019, March 4). On disappearing bookstores. Retrieved from Steamthing.com. website: https://steamthing.com/2019/03/on-disappearing-bookstores.html 
Dvali, T. (2020, March 17). Almost everyone who valued me is in the village cemetery. Interview with Giorgi Lobzhanidze. Retrieved from Radio Freedom website: https://www.radiotavisuple-

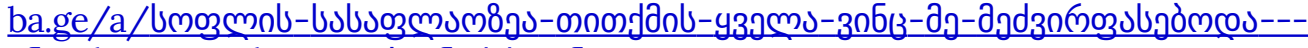

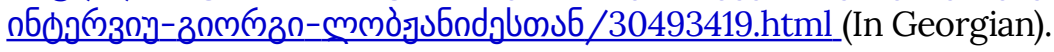

Fischer, Ch. (2013, October). Seattle's Disappearing Bookstores. A recovering used book clerk laments the steady disappearance of a last great place for meandering. Retrieved from Seattle Magazine website: https://www.seattlemag.com/article/seattles-disappearing-bookstores

Galaishvili, D. (2018, September, 23). Cultural industry and demand. Retrieved from: Demo.ge website: https://www.demo.ge/index.php?do=full\&id=1589 (In Georgian).

Graham, R. (2019, July 11). The Decline of the Christian Bookstore. Yes, they sell sanitized music and "Jesus junk." But something important gets lost when Christian bookstores disappear. Retrieved from Slate. A daily magazine website: https://slate.com/human-interest/2019/07/christian-bookstores-closing-lifeway-familychristian-stores.html

Hardin, G. (1969, December 13). The Tragedy of the Commons. Retrieved from Science website: https://science.sciencemag.org/content/162/3859/1243.full

Johnson, Ch. (2016, October 11).What do Americans lose if bookstores disappear? More than you think. Retrieved from Deseret News website: https://www.deseret.com/2016/10/11/20597947/what-do-americans-lose-if-bookstoresdisappear-more-than-you-think

Kevanishvili, E. (2019, March 29). Books in the mill - a place to read. Retrieved from Radio Freedom

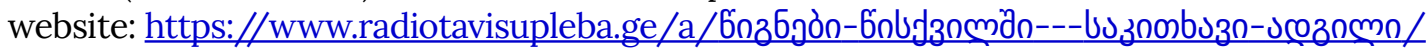
29849150.html (In Georgian).

Koyava, R. (2015, March 18). Consumers' community. Retrieved from Demo.ge website: https://www.demo.ge/index.php?do=full\&id=1217 (In Georgian).

Kukhalashvili, E. (2013, March 4). The fear of the computer is a sign of illiteracy. Retrieved from NewPress website: http://newpress.ge/staties_id/308 (In Georgian).

Kyrchanoff, M. (2016). Dystopian discourse and national identity in Russian prose of the 2010s. Toronto Slavic Quarterly, (58). Retrieved from: http://sites.utoronto.ca/tsq/58/Kyrchanof58.pdf

Kyrchanoff, M. (2017). "Shakespeare... was Russian writer probably because the name does not like Chinese": two libroutopias in post-Soviet literatures of Belarus and Russia. Toronto Slavic Quarterly, (60). Retrieved from: http://sites.utoronto.ca/tsq/60/Kyrchanoff60.pdf

Le Guin, U. (2016). Words Are My Matter: Writings About Life and Books, 2000-2016, L. - NY.: Small Beer Press. Retrieved from Ursula Le Guin website: https://www.ursulakleguin.com/words-aremy-matter

Mchedlidze, T. (2011, November 2). After modernisation. Retrieved from Demo.ge website: https://www.demo.ge/index.php?do=full\&id=847 (In Georgian).

McLuhan, M. (1962). The Gutenberg Galaxy: The Making of Typographic Man. Toronto: University of Toronto Press.

Miller, L. (2008). Reluctant capitalists: Bookselling and the culture of consumption, Chicago: University of Chicago Press. 
O'Connor, C. (2016, September 12). Disappearing Bookstores. Why our bookstores are disappearing, and why you should care. Retrieved from Odyssey website: https://www.theodysseyonline.com/disappearing-bookstores

Raffaelli, R. (2020, January). Reinventing Retail: The Novel Resurgence of Independent Bookstores. In Harvard Business School Working Papers. Retrieved from: https://www.hbs.edu/faculty/Publication\%20Files/20-068 c19963e7-506c-479a-beb4bb339cd293ee.pdf

Sastumlishvili, N. (2019, March 2). About writers and novels. Retrieved from Arili website:

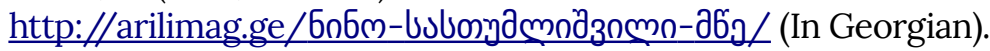

Shoshiashvili, N. (2016, March 26). History has lost historical sense. Retrieved from European.ge website: http://european.ge/nukri-shoshiashviuli-sazrisi/(In Georgian).

Takamitsu Sawa, (2020, April 19). What we'll miss when bookstores disappear. Retrieved from The Japan Times website.

https://www.japantimes.co.jp/opinion/2020/04/19/commentary/japan-commentary/wellmiss-bookstores-disappear/

Tskhvediani, Ts. (2017, September 28). City - Dramatic Works. Retrieved from Liberal website: http:// liberali.ge/articles/view/31493/qalaqi--dramatuli-natsarmoebi (In Georgian).

Urushadze, I., \& Pirtskhalaishvili, G. (2018, August 5). User of literature. Retrieved from Arili website:

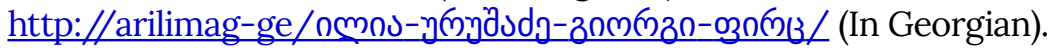

